\title{
Trait Mindfulness, Affective Symptoms and Quality of Life in People with Non-Hodgkin's Lymphoma
}

\author{
Susan Ellis ${ }^{1,2}$, Rhonda F. Brown' ${ }^{1,3}$, Einar B. Thorsteinsson' ${ }^{1}$, Colin Perrott ${ }^{1}$ \\ ${ }^{1}$ School of Behavioural, Cognitive \& Social Sciences, University of New England, Armidale, Australia \\ ${ }^{2}$ School of Psychology, University of Queensland, Brisbane, Australia \\ ${ }^{3}$ Research School of Psychology, The Australian National University, Acton, Australia \\ Email: susan.ellis@uqconnect.edu.au
}

Received 23 August 2014; revised 20 September 2014; accepted 15 October 2014

Academic Editor: Nelson Hamerschlak, Sociedade Beneficentelsraelita Brasileira Albert Einstein, Brazil

Copyright (C) 2014 by authors and Scientific Research Publishing Inc.

This work is licensed under the Creative Commons Attribution International License (CC BY).

http://creativecommons.org/licenses/by/4.0/

(c) (i) Open Access

\section{Abstract}

Purpose: The construct of mindfulness has previously been examined in cancer patients, as has the efficacy of mindfulness-based treatments. However, it has not been examined in people with non-Hodgkin's lymphoma (NHL). NHL is one of the most distressing cancer diagnoses being associated with high levels of depression, anxiety and poor quality of life (QOL). In this study, we evaluated the experience of depression, anxiety, stress and QOL in people with NHL and the relationship of these states to a trait-based measure of mindfulness. Method: Participants were 125patients and survivors of NHL who had been diagnosed at least 2 years ago. They completed an online questionnaire asking about their recent experiences of depression, anxiety, stress, QOL, mindfulness and its components, and the practice of mindfulness-meditation. Results: Controlling for disease status, high overall mindfulness and mindful-acceptance were related to lower levels of depression, anxiety, and stress. Mindful-attention, high overall mindfulness and mindful-acceptance were all related to better QOL, after controlling for disease and marital status. Conclusions: The results suggest that attending to one's thoughts and feelings may be sufficient to experience good quality of life, but it may be insufficient to buffer against the potential for psychological distress. However, the mindful-acceptance of unpleasant, threatening or painful thoughts and feelings may be necessary to prevent or reduce the impact of affective symptoms such as depression and anxiety. Implications for cancer survivors: understanding the potential role played by mindfulness in informing well-being outcomes in NHL patients and survivors may assist in the development of appropriate interventions, aimed at improving their mental health. 


\section{Keywords}

\section{Lymphoma, Oncology, Mindfulness, Depression, Anxiety, Stress, Quality of Life}

\section{Introduction}

In this study, we evaluated patients and survivors of non-Hodgkin's lymphoma (NHL), in particular, a rare, indolent and mostly incurable subtype called Waldenstrom's Macroglobulinemia (WM), also known as lymphoplasmacytic lymphoma. NHL is the most common type of blood cell cancer, accounting for around $4 \%$ of all cancer diagnoses in Australia [1]. There are more than 30 subtypes of NHL including WM [2]. Most cases of NHL are diagnosed in later life, and the incidence tends to increase with advancing age, with a median age of onset of 66 years. WM comprises 1\% of all diagnosed NHL cases, and has a similar median age of onset of 63 years [3]. The treatment of NHL varies dependent upon the disease category, with WM (being an indolent subtype) often involving a "watch and wait" therapeutic approach [4]. The mean 5-year survival rate for people diagnosed with NHL is around 69\% [4], whereas the 5-year survival rate for people with WM is between 36 to $87 \%$, depending on their risk category [5].

Many studies have examined the psychological experiences of cancer patients, but few have investigated the specific experiences of people with NHL or WM. Thus, it is unclear whether the illness experience of people with NHL is similar to or different from that of other forms of cancer. In the literature, cancer diagnosis and treatment is described as a psychologically challenging experience. Patients may have to deal with unpleasant symptoms, multiple tests, ongoing treatment, loss of functioning [6] [7], and uncertainty about their future health [8]. In some cases, the cancer experience overwhelms the patient's coping resources as they attempt to adjust to the disruptions caused by the illness and its treatment [8] [9].

As a consequence, a significant proportion of cancer patients report experiencing clinically-relevant depression and/or anxiety at some point during their illness or recovery [10]. Approximately 50\%of cancer patients and survivors have been reported to experience significant distress at diagnosis, and around 30\%were still distressed two or more years later [11]. However, more recent studies report lower prevalence estimates of psychological distress, for example, $20 \%$ to one-third of cancer patients across the illness trajectory [12] [13]. Nonetheless, a significant proportion of cancer patients and survivors continue to experience unpleasant psychological, emotional, spiritual, and social situations that may inhibit their ability to cope with cancer and its treatment [14]. Moreover, almost one-third of cancer survivors report experiencing trauma-related symptoms comparable to those who have survived catastrophic life-threatening events (e.g., violent interpersonal attack; [15]).

Only a small literature has examined psychological distress in patients and survivors of NHL, although NHL is rated among the top five cancers causing psychological distress out of 14 different cancer diagnoses (i.e., prevalence of 36\%; [16]), suggesting that lymphoma may be an especially distressing form of cancer to deal with. However, in another study, nearly two-thirds (63\%) of NHL patients reported clinically significant depression or anxiety up to 1-year after diagnosis [17], and this NHL-specific distress was found to persist for up to 3-years after treatment [18].

The correlates of depression and anxiety have been examined in cancer patients. For example, depression and anxiety have been shown to be associated with poorer treatment adherence [6] [19] and treatment response [20]. In addition, depression has been shown to be strongly correlated with worse physical symptoms in cancer patients (e.g., pain; [21]), later cancer stage [22], shorter survival time [23], poorer QOL [24] [25], and prior depression and comorbid anxiety [26]. Similarly, high anxiety was related to increased pain, fear of recurrence [27], and worse QOL [6].

However, no studies have evaluated the correlates of depression, anxiety, stress, and QOL in NHL patients, although its treatment has been shown to impair QOL [28]-[30]. Nor have any psychological constructs with the potential to inform treatment of psychological distress in NHL been examined. Thus, in this study, we examined mindfulness and its subcomponents and their relationship to affective symptoms (i.e., depression, anxiety), stress, and QOL in people with NHL.

Mindfulness has recently been explored as a construct of interest in the cancer literature, although the individual components of mindfulness have not been examined. For example, the expression of the trait is related to 
better mental and physical health in cancer patients (e.g., less depression and anxiety; [31]). The concept of mindfulness originated in Eastern contemplative traditions, especially Buddhism, where it is recognized as the cornerstone of the path towards liberation from personal suffering [32]. The concept has recently been adopted by Western cultures, where it is somewhat differently described as the conscious awareness of and purposeful attention to one's present-moment experiences, in a non-judgmental and accepting way [33]. This approach is closely aligned with the original concept of mindfulness, but its integration into Western culture has led to several divergent conceptualizations of the construct. Thus, there are a variety of different approaches to the measurement of mindfulness. For example, Brown and Ryan [34] described mindfulness as a unidimensional factor related to the regulation of attention to present-moment experiences, and they therefore calculated a single total score on the Mindful Attention and Awareness Scale.

In contrast, some conceptualizations of the construct have evaluated multiple dimensions. For example, using an exploratory factor analysis, Baer, Smith, Hopkins, Krietemeyer, and Toney [35] showed that mindfulness was comprised of five factors, and this led to the development of the Five Factor Mindfulness Questionnaire. However, Bishop et al. [36] proposed that a two-component theoretical model of mindfulness better conceptualized the construct, with the two sub-components being mindful-attention and mindful-acceptance. The attention component relates to the deliberate regulation of attention to one's immediate experiences (e.g., thoughts, feelings, and physical sensations), while the acceptance component refers to an open, receptive, and accepting attitude to experience that does not involve minimizing, ignoring, or judging, especially when the experiences are distressing.

Consistent with the above theoretical approach, Coffey, Hartman, and Fredrickson [37] developed the Carolina Empirically Derived Mindfulness Inventory (CEDMI). This trait-based measure is comprised of two subscales, present-centred attention (i.e., mindful-attention) and acceptance of experience (i.e., mindful-acceptance). The authors reported that high mindful-attention was directly associated with wellbeing (e.g., flourishing) and indirectly related to low psychological distress (i.e., depression, anxiety) in university students. The results suggest that clarity of emotional experience may indirectly reduce a person's perception of distress and enhance their perceptions of wellbeing [37]. In contrast, high mindful-acceptance was strongly and directly correlated with low psychological distress and better wellbeing, suggesting that acceptance may directly buffer against the potential for psychological distress. However, only two studies have examined trait mindfulness in cancer patients, and none have evaluated the sub-components of mindfulness. Both of these studies showed that mindfulness was associated with lower depression, anxiety, and stress levels in breast and prostate cancer patients [34] and in a mixed sample of cancer patients [38]. However, no studies have evaluated mindfulness levels in lymphoma patients. Thus, in this study, we utilized the well-accepted two component theoretical model of mindfulness [36], and Coffey et al.'s [37] CEDMI trait measure of the construct to evaluate mindfulness-based predictors of affective symptoms (i.e., depression, anxiety), psychological stress, and QOL in patients and survivors of NHL.

Based on the aforementioned literature, it was expected that: 1) high overall mindfulness and mindful-acceptance will be associated with lower depression levels; 2) high overall mindfulness and mindful-acceptance will be associated with lower anxiety levels; 3) high overall mindfulness and mindful-acceptance will be associated with lower stress levels; and 4) high overall mindfulness, mindful-attention, and mindful-acceptance will be associated with better overall QOL.

\section{Method}

\subsection{Participants}

This study was conducted with full human research ethics committee approval from the University of New England. Potential participants were recruited by advertisements placed on two lymphoma support websites: WM Topics (www.wmtopics.com) from April to August 2011, and the Australian Leukaemia Foundation (www.leukaemia.org.au) from July to August 2011. An a priori power analysis using G*Power 3.1 [39] indicated that a sample of 123 was required, assuming a medium effect size of $f^{2}=0.15$, four predictors (i.e., two demographics, two mindfulness sub-scores), alpha set at 0.05 , and power of 0.90 [40]. Thus, a sample size of 125 was considered adequate for the planned analyses. Inclusion criteria for the study were age 18 years or over and adiagnosis of NHL, including WM, two or more years ago.

Two-hundred-six people clicked on the study URL and entered the study information page. Of these, 81 failed 
to progress to the study questionnaire; the non-responders were excluded from analysis, leaving 125 participants. Most participants (89.6\%) were recruited via the WM Topics website and $10.4 \%$ were recruited via the Leukaemia Foundation website.

Seventy-one males (56.8\%) and 54 (43.2\%) females participated in the study, with ages ranging from 32 - 92 years $(M=63.91, S D=9.60)$. Most participants were partnered (i.e., married or in a de facto relationship, $n=$ 103, 82.4\%) and $17.6 \%$ were not partnered. Most had completed a trade certificate or university/postgraduate degree ( $n=103,82.4 \%$ ), and the remainder had completed some or all of high school (17.6\%). About one-half of the sample worked full-time, part-time, or casual $(n=64,51.2 \%)$, and one-half were retired or unemployed (48.8\%).

Most of the participants ( $n=112,89.6 \%$ ) were survivors of WM, and the remainder $(10.4 \%)$ were survivors of NHL, other than WM. Of the respondents, 30\% $(n=37)$ confirmed their lymphoma diagnosis by uploading a medical report to the survey website, or agreed to have their doctor confirm the diagnosis. The remainder consented to their doctor providing the details but the doctors did not comply with the information requests. Time since diagnosis ranged from 2 to 18 years $(M=5.99, S D=3.79)$. About three-quarters $(n=92,73.6 \%)$ of the sample reported they were currently in remission or had stable disease. Most reported no prior or current cancer diagnosis $(n=75)$, although 40\% $(n=50)$ indicated that they had another diagnosed medical illness (e.g., asthma, hypertension, diabetes mellitus type-2), and one-third ( $n=42,33.6 \%)$ were currently receiving treatment for their lymphoma.

\subsection{Measures}

The survey was delivered in an online format using the web-based survey software, Qualtrics (www.qualtrics.com). The survey asked about demographics (i.e., sex, age, marital status, education level, employment), medical details (i.e., type of lymphoma, time since diagnosis, disease status, current medication/ treatment, other cancer diagnoses, other medical diagnoses), the current practice of mindfulness-based meditation, and included the scales mentioned below.

\subsubsection{Carolina Empirically Derived Mindfulness Inventory (CEDMI)}

The CEDMI [37] was used to assess trait mindfulness. Two subscales, mindful-attention (8-item) and mindfulacceptance (14-item) assessed the constructs using 5-point Likert type scales ranging from 1 (almost never) to 5 (almost always), with high scores indicating greater expression of the trait. Subscale scores ranged from 8 to 40 (attention) and 14 to 70 (acceptance). The subscales have high reported construct validity and adequate to high internal consistencies, with Cronbach's alphas of 0.74 (attention) and 0.90 (acceptance; [37]). In the present study, the internal consistencies were 0.81 for overall mindfulness, 0.86 for attention, and 0.88 for acceptance.

\subsubsection{Depression Anxiety and Stress Scales-Short-Form (DASS-21)}

The DASS-21 [41] was used to assess depression, anxiety and stress symptoms over the past week. The DASS21 comprises three 7-item subscales assessing depression, anxiety, and stress, using 4-point Likert type scales ranging from 0 (did not apply to me at all) to 3 (applied to me very much/most of the time), with high scores indicating greater distress levels. The scale has high concurrent validity [42], and its internal consistency is also high, with Cronbach's alphas of 0.92 for depression, 0.81 for anxiety, and 0.86 for stress [41]. In the present study, the internal consistencies were 0.86 for depression, 0.80 for anxiety, and 0.80 for stress.

\subsubsection{Functional Assessment of Cancer Therapy-General Version 4 (FACT-G)}

The FACT-G [43] was used to assess overall QOL. The 27-item scale is comprised of four subscales: physical, social, emotional and functional wellbeing, although in this study, only overall QOL was reported, consistent with prior approaches in the literature [44]. Participants were asked to respond to statements using 5-point Likert type scales ranging from 0 (not at all) to 4 (very much), with high scores indicating better QOL. The scale has high reported convergent and discriminant validity, and high internal consistency, with a Cronbach's alpha of 0.89 [43]. In this study, the internal consistency was high, 0.90 .

\subsection{Procedure}

Interested participants clicked on the study URL to enter the study information page. They were informed that 
their involvement was voluntary, their responses would be handled confidentially, and that they were free to withdraw from the study at any time. They were required to provide their consent to participate in the study prior to commencing the online survey. The survey was customized to permit participants to leave and re-enter as they wished, thereby enabling them to complete the survey over one or more sittings. They were requested to answer each survey item as honestly and openly as possible.

\subsection{Statistical Analysis}

All statistical analyses were conducted using Predictive Analytic Software (PASW) Statistics program, version 18 for Macintosh. Of the study variables, only overall mindfulness was normally distributed. Parametric and non-parametric tests were conducted and the results were compared. The same pattern of results was shown in all of the analyses, whether transformed or untransformed data were used. For ease of interpretation, only the raw data and parametric test results are reported here.

Four multivariate outliers were identified with Mahalanob is distance values greater than critical chi-squared values ( $p<0.001$ ), but all the Cook's distance maximum values were below 1.00 [45], and all were deemed to be clinically relevant (e.g., severe depression). All regressions were therefore conducted with and without the outliers. The same pattern of results was obtained in all the analyses, and so the outliers were retained in the regression analyses. All assumptions of normality, linearity, homoscedasticity, and independence were reviewed and were found to be tenable. There was no evidence of multi-collinearity in regression analyses, with all tolerance values above 0.96 .

\section{Results}

Means and standard deviations of the key study variables are presented in Table 1. The participants reported high mean levels of trait mindfulness and QOL; relatively low levels of depression, anxiety, and stress; and moderate levels of mindful-attention. Only a minority of participants (9\%) reported practicing mindfulnessbased meditation more than three times per week.

A correlation matrix of the independent variables (i.e., overall mindfulness, mindful-attention, and mindfulacceptance), possible covariates (i.e., demographic and medical details) and dependent variables (i.e., depression, anxiety, stress, and QOL) is provided in Table 2. Regarding possible third variables, anxiety and depression scores only had a small correlation with the demographic and medical variables, but high stress was correlated with disease status (i.e., not in remission/unstable disease), and high QOL was correlated with marital status

\begin{tabular}{|c|c|c|c|c|}
\hline \multirow{2}{*}{ Scale } & \multirow{2}{*}{$M$} & \multirow{2}{*}{$S D$} & \multicolumn{2}{|c|}{ Range of Scores } \\
\hline & & & Potential & Actual \\
\hline \multicolumn{5}{|l|}{ Mindfulness (CEDMI) } \\
\hline Overall & 84.74 & 9.82 & $22-110$ & $56-108$ \\
\hline Mindful Attention & 22.42 & 7.12 & $8-40$ & $10-39$ \\
\hline Mindful Acceptance & 62.32 & 7.63 & $14-70$ & $32-70$ \\
\hline \multicolumn{5}{|c|}{ Psychological Distress (DASS-21) } \\
\hline Depression & 2.46 & 3.07 & $0-21$ & $0-16$ \\
\hline Anxiety & 1.90 & 2.44 & $0-21$ & $0-16$ \\
\hline Stress & 3.36 & 3.21 & $0-21$ & $0-19$ \\
\hline \multicolumn{5}{|l|}{ Quality of Life (FACT-G) } \\
\hline Overall & 85.14 & 13.37 & $0-108$ & $50-106$ \\
\hline
\end{tabular}

Note: CEDMI = Carolina Empirically Derived Mindfulness Inventory; DASS-21 = Depression, Anxiety, Stress Scales-Short Form; FACT-G = Functional Assessment of Cancer Therapy-General Version. 
Table 2. Pearson's correlations between demographic/medical variables, psychological distress, quality of life, and mindfulness variables.

\begin{tabular}{|c|c|c|c|c|c|c|}
\hline Variable & Depression & Anxiety & Stress & QOL & Overall mindfulness & Mindful attention \\
\hline \multicolumn{7}{|l|}{ Demographic variables } \\
\hline Sex (1 = Male, 2 = Female) & -0.01 & 0.07 & -0.02 & 0.08 & & \\
\hline Age (Years) & -0.05 & -0.08 & -0.17 & 0.04 & & \\
\hline Marital status ( 1 = Partnered, 2 = Not partnered $)$ & 0.08 & 0.11 & 0.13 & $-0.24^{* *}$ & & \\
\hline Education level (1 = Lower, 2 = Higher) & 0.06 & -0.03 & 0.09 & 0.01 & & \\
\hline Employment (1 = Working, 2 = Not working) & 0.06 & 0.12 & 0.10 & -0.15 & & \\
\hline Mindfulness-based meditation ( $1=$ Yes, $2=$ No $)$ & 0.08 & -0.02 & -0.12 & -0.07 & & \\
\hline \multicolumn{7}{|l|}{ Medical variables } \\
\hline Diagnosis details (1 = WM, 2 = NHL) & -0.13 & -0.09 & -0.15 & 0.13 & & \\
\hline Time since diagnosis (Years) & 0.13 & 0.10 & 0.13 & -0.16 & & \\
\hline Disease status ( 1 = Not active, 2 = Active) & 0.15 & 0.14 & $0.21^{*}$ & $-0.33^{* *}$ & & \\
\hline Medication/treatment (1 = Yes, 2 = No) & -0.01 & -0.01 & -0.07 & 0.17 & & \\
\hline Other cancer diagnosis ( 1 = Yes, 2 = No) & 0.02 & 0.01 & -0.03 & 0.03 & & \\
\hline Other medical illness ( 1 = Yes, 2 = No) & -0.07 & -0.17 & -0.03 & 0.11 & & \\
\hline \multicolumn{7}{|l|}{ Depression } \\
\hline Anxiety & $0.73^{* * *}$ & & & & & \\
\hline Stress & $0.64^{* * *}$ & $0.68^{* * *}$ & & & & \\
\hline QOL & $-0.73^{* * *}$ & $-0.54^{* * *}$ & $-0.57^{* * *}$ & & & \\
\hline Overall mindfulness & $-0.48^{* * *}$ & $-0.21^{*}$ & $-0.31^{* * *}$ & $0.40^{* * *}$ & & \\
\hline Mindful attention & -0.04 & 0.10 & 0.03 & 0.15 & $0.64^{* * * *}$ & \\
\hline Mindful acceptance & $-0.58^{* * *}$ & $-0.36^{* * *}$ & $-0.43^{* * *}$ & $0.38^{* * *}$ & $0.69^{* * *}$ & -0.11 \\
\hline
\end{tabular}

Note: QOL = Quality Of Life; WM = Waldenstrom's Macroglobulinemia; NHL = Non-Hodgkin’s Lymphoma. ${ }^{*} p<0.05$, two-tailed; ${ }^{* *} p<0.01$, twotailed; ${ }^{* * *} p<0.001$, two-tailed.

(i.e., partnered) and remission/stable disease. Thus, the above covariates were controlled at step 1 in the regression analyses for stress and QOL, respectively.

Eight hierarchical or standard multiple regression analyses were conducted to evaluate mindfulness-based predictors of depression, anxiety, stress, and QOL. Demographicor medical factors that were significantly correlated with dependent variables were entered at step 1 in the hierarchical regression analysis, and independent variables were entered as step 2 . Overall mindfulness and mindfulness sub-scores were examined separately in these analyses.

\subsection{Mindfulness and Depression}

A standard multiple regression analysis was conducted to examine whether overall mindfulness was related to depression, see Table 3. Overall mindfulness explained $23.0 \%$ of the variance in depression score, $R=0.48$, $F(1,123)=36.98, p<0.001$, indicating that high overall mindfulness was related to lower depression levels. A separate regression analysis evaluated whether mindful-attention and mindful-acceptance were related to depression score, see Table 3. Together, the variables explained 35.0\% of the variance in depression score, $R=$ $0.59, F(2,122)=32.91, p<0.001$, but only high mindful-acceptance was significantly related to lower depression score. 
Table 3. Standard multiple regressions for mindfulness variables predicting depression.

\begin{tabular}{|c|c|c|c|c|c|c|c|}
\hline \multirow{2}{*}{ Predictor } & \multicolumn{2}{|c|}{ Unstandardized } & \multicolumn{2}{|c|}{$95 \%$ CI } & \multirow[b]{2}{*}{$\beta$} & \multirow[b]{2}{*}{$s r^{2}$} & \multirow[b]{2}{*}{$R^{2}$} \\
\hline & $B$ & $S E$ & $L L$ & $U L$ & & & \\
\hline Model 1 & & & & & & & $0.23^{* * *}$ \\
\hline Constant & 15.20 & 2.11 & 11.03 & 19.37 & & & \\
\hline Overall mindfulness & -0.15 & 0.03 & -0.20 & -0.10 & $-0.48^{* * *}$ & 0.23 & \\
\hline Model 2 & & & & & & & $0.35^{* * *}$ \\
\hline Constant & 18.41 & 2.06 & 14.33 & 22.48 & & & \\
\hline Mindful attention & -0.05 & 0.03 & -0.11 & 0.02 & -0.11 & 0.01 & \\
\hline Mindful acceptance & -0.24 & 0.03 & -0.30 & -0.18 & $-0.59^{* * *}$ & 0.35 & \\
\hline
\end{tabular}

\subsection{Mindfulness and Anxiety}

A standard multiple regression analysis was conducted to examine whether overall mindfulness was related to anxiety, see Table 4. Overall mindfulness explained $4.3 \%$ of the variance in anxiety score, $R=0.21 F(1,123)=$ 5.59, $p=0.020$, indicating that high overall mindfulness was related to lower anxiety levels. A separate regression analysis evaluated whether mindful-attention and mindful-acceptance were related to anxiety score, see Table 4 . Together, the variables explained $13.0 \%$ of the variance in anxiety score: $R=0.36, F(2,122)=9.25$, $p<0.001$, but only high mindful-acceptance was significantly related to lower anxiety score.

\subsection{Mindfulness and Stress}

A hierarchical multiple regression analysis was conducted to examine whether overall mindfulness was related to high stress, see Table 5. At step 1 , disease status explained $4.2 \%$ of the variance in stress scores, $R=0.21$, $F(1,123)=5.41, p=0.022$. At step 2 , overall mindfulness explained an additional $8.4 \%$ of variance in stress, $F_{\text {Change }}(1,122)=11.68, p=0.001$, and the overall variance explained by the model was $12.6 \%, R=0.35, F(2,122)$ $=8.78, p<0.001$. Thus, after controlling for disease status, high overall mindfulness was related to lower stress scores. A separate regression analysis evaluated whether mindful-attention and mindful-acceptance were related to stress, see Table 5. At step 1, disease status explained $4.2 \%$ of the variance in stress, $R=0.21, F(1,123)=$ $5.41, p=0.022$. At step 2, mindful-attention and mindful-acceptance explained an additional $17.1 \%$ of variance in stress, $F_{\text {Change }}(2,121)=13.16, p<0.001$, and the overall variance explained by the model was $21.3 \%, R=0.46$, $F(3,121)=10.93, p<0.001$. Thus, after controlling for disease status, high mindful-acceptance (but not mindful-attention) was significantly related to high stress.

\subsection{Mindfulness and Quality of Life}

A hierarchical multiple regression analysis was conducted to examine whether overall mindfulness was related to higher QOL, see Table 6. At step 1, disease and marital status explained $14.5 \%$ of the variance in QOL, $R=$ $0.38, F(2,122)=10.36, p<0.001$. At step 2 , overall mindfulness explained an additional $12.7 \%$ of variance in QOL, $F_{\text {Change }}(1,121)=21.18, p<0.001$, and the overall variance explained by the model was $27.2 \%, R=0.52$, $F(3,121)=15.11, p<0.001$. Thus, after controlling for disease and marital status, high overall mindfulness was significantly related to higher QOL. A separate regression analysis evaluated whether mindful-attention and mindful-acceptance were related to QOL, see Table 6. At step 1, disease and marital status explained $14.5 \%$ of the variance in QOL, $R=0.38, F(2,122)=10.36, p<0.001$. At step 2, mindful-attention and mindful-acceptance explained an additional $14.5 \%$ of variance in QOL, $F_{\text {Change }}(2,120)=12.25, p<0.001$, and the overall variance explained by the model was $29.0 \%, R=0.54, F(4,120)=12.26, p<0.001$. Thus, after controlling for disease and marital status, high mindful-attention and mindful-acceptance were significantly related to better QOL, with mindful-acceptance being the strongest individual predictor of QOL. 
Table 4. Standard multiple regressions for mindfulness variables predicting anxiety.

\begin{tabular}{|c|c|c|c|c|c|c|c|}
\hline \multirow{2}{*}{ Predictor } & \multicolumn{2}{|c|}{ Unstandardized } & \multicolumn{2}{|c|}{$95 \%$ CI } & \multirow[b]{2}{*}{$\beta$} & \multirow[b]{2}{*}{$s r^{2}$} & \multirow[b]{2}{*}{$R^{2}$} \\
\hline & $B$ & $S E$ & $L L$ & $U L$ & & & \\
\hline Model 1 & & & & & & & $0.04^{*}$ \\
\hline Constant & 6.29 & 1.87 & 2.59 & 9.99 & & & \\
\hline Overall mindfulness & -0.05 & 0.02 & -0.10 & -0.01 & $-0.21^{*}$ & 0.04 & \\
\hline Model 2 & & & & & & & $0.13^{* * *}$ \\
\hline Constant & 8.48 & 1.89 & 4.73 & 12.22 & & & \\
\hline Mindful attention & 0.02 & 0.03 & -0.04 & 0.08 & 0.06 & $<0.01$ & \\
\hline Mindful acceptance & -0.11 & 0.03 & -0.17 & -0.06 & $-0.36^{* * *}$ & 0.12 & \\
\hline
\end{tabular}

Table 5. Hierarchical multiple regressions for mindfulness variables predicting stress.

\begin{tabular}{|c|c|c|c|c|c|c|c|}
\hline \multirow{2}{*}{ Predictor } & \multicolumn{2}{|c|}{ Unstandardized } & \multicolumn{2}{|c|}{$95 \%$ CI } & \multirow[b]{2}{*}{$\beta$} & \multirow[b]{2}{*}{$s r^{2}$} & \multirow[b]{2}{*}{$R^{2}$} \\
\hline & $B$ & $S E$ & $L L$ & $U L$ & & & \\
\hline \multicolumn{8}{|l|}{ Model 1} \\
\hline Step 1 & & & & & & & $0.04^{*}$ \\
\hline Constant & 1.48 & 0.86 & -0.21 & 3.17 & & & \\
\hline Disease status & 1.49 & 0.64 & 0.22 & 2.75 & $0.21 *$ & 0.04 & \\
\hline Step 2 & & & & & & & $0.13^{* * *}$ \\
\hline Constant & 9.85 & 2.58 & 4.74 & 14.97 & & & \\
\hline Disease status & 1.24 & 0.62 & 0.02 & 2.46 & $0.17^{*}$ & 0.03 & \\
\hline Overall mindfulness & -0.10 & 0.03 & -0.15 & -0.04 & $-0.29^{* *}$ & 0.08 & \\
\hline \multicolumn{8}{|l|}{ Model 2} \\
\hline Step 1 & & & & & & & $0.04^{*}$ \\
\hline Constant & 1.48 & 0.86 & -0.21 & 3.17 & & & \\
\hline Disease status & 1.49 & 0.64 & 0.22 & 2.75 & $0.21^{*}$ & 0.04 & \\
\hline Step 2 & & & & & & & $0.21^{* * *}$ \\
\hline Constant & 12.84 & 2.59 & 7.70 & 17.97 & & & \\
\hline Disease status & 1.17 & 0.59 & 0.01 & 2.34 & $0.16^{*}$ & 0.03 & \\
\hline Mindful attention & $<0.01$ & 0.04 & -0.08 & 0.07 & -0.01 & $<0.01$ & \\
\hline Mindful acceptance & -0.18 & 0.03 & -0.24 & -0.11 & $-0.42^{* * *}$ & 0.17 & \\
\hline
\end{tabular}

\section{Discussion}

The results of the present study suggest that high overall mindfulness and mindful-acceptance (but not mindfulattention) is related to lower depression, anxiety, and stress levels. The results are consistent with Hypotheses 1 to 3, and prior study results indicating that high overall mindfulness is related to lower depression [46], anxiety [47], and stress levels [48], in cancer patients, although the subcomponents of mindfulness have not previously been examined in this population. 
Table 6. Hierarchical multiple regressions for mindfulness variables predicting quality of life.

\begin{tabular}{|c|c|c|c|c|c|c|c|}
\hline \multirow{2}{*}{ Predictor } & \multicolumn{2}{|c|}{ Unstandardized } & \multicolumn{2}{|c|}{$95 \%$ CI } & \multirow[b]{2}{*}{$\beta$} & \multirow[b]{2}{*}{$s r^{2}$} & \multirow[b]{2}{*}{$R^{2}$} \\
\hline & B & $S E$ & $L L$ & $U L$ & & & \\
\hline \multicolumn{8}{|l|}{ Model 1} \\
\hline Step 1 & & & & & & & $0.15^{* * *}$ \\
\hline Constant & 104.56 & 4.52 & 95.62 & 113.51 & & & \\
\hline Disease status & -9.05 & 2.56 & -14.12 & -3.98 & $-0.30^{* *}$ & 0.09 & \\
\hline Marital status & -6.80 & 2.96 & -12.65 & -0.93 & $-0.19^{*}$ & 0.04 & \\
\hline Step 2 & & & & & & & $0.27^{* * *}$ \\
\hline Constant & 61.20 & 10.31 & 40.79 & 81.61 & & & \\
\hline Disease status & -7.81 & 2.39 & -12.53 & -3.08 & $-0.26^{*}$ & 0.06 & \\
\hline Marital status & -6.51 & 2.74 & -11.95 & -1.08 & $-0.19^{*}$ & 0.03 & \\
\hline Overall mindfulness & 0.49 & 0.11 & 0.28 & 0.70 & $0.36^{* * *}$ & 0.13 & \\
\hline \multicolumn{8}{|l|}{ Model 2} \\
\hline Step 1 & & & & & & & $0.15^{* * *}$ \\
\hline Constant & 104.56 & 4.52 & 95.62 & 113.51 & & & \\
\hline Disease status & -9.05 & 2.56 & -14.12 & -3.98 & $-0.30^{* *}$ & 0.09 & \\
\hline Marital status & -6.80 & 2.96 & -12.65 & -0.93 & $-0.19^{*}$ & 0.04 & \\
\hline Step 2 & & & & & & & $0.29^{* * *}$ \\
\hline Constant & 55.69 & 10.72 & 34.47 & 76.91 & & & \\
\hline Disease status & -7.67 & 2.37 & -12.36 & -2.99 & $-0.25^{* *}$ & 0.06 & \\
\hline Marital status & -6.57 & 2.72 & -11.96 & -1.18 & $-0.19^{*}$ & 0.03 & \\
\hline Mindful attention & 0.32 & 0.15 & 0.03 & 0.61 & $0.17^{*}$ & 0.03 & \\
\hline Mindful acceptance & 0.64 & 0.14 & 0.37 & 0.91 & $0.36^{* * *}$ & 0.13 & \\
\hline
\end{tabular}

Note: $s r^{2}=$ squared semi-partial correlation. ${ }^{*} p<0.05 .{ }^{* *} p<0.01 .{ }^{* * *} p<0.001$.

These findings are also consistent with those of Coffey et al. [37] who found that mindful-acceptance was directly related to lower depression and anxiety levels, but mindful-attention was only indirectly related to the states in university students. Similarly, better QOL was found to be related to higher overall mindfulness, mindful-attention and mindful-acceptance, after controlling for disease and marital status. These results are consistent with Hypothesis 4 and prior study results indicating that high overall mindfulness is related to better QOL in cancer patients [34] [49].

Taken together, the results suggest that mindful-acceptance was the key mindfulness component that informed and influenced the expression of affective symptoms (i.e., depression, anxiety) and stress perceptions in study respondents. In contrast, high mindful-attention and mindful-acceptance were apparently relevant to their respondent's subjective assessment of QOL. Alternatively, the results may simply reflect that the experience of stress and distress interfered with the experience of mindfulness in some people, as they began to ruminate, worry or possibly catastrophize about their current medical situation. Additionally, it is possible that trauma-related symptoms (e.g., intrusions) may have reduced the capacity of some individuals to experience mindfulness, although it was beyond the scope of this study to assess these psychological symptoms. Finally, the indolent nature of WM and the common "watch and wait" strategy to disease management may have led some individuals to worry unduly about their situation.

Somewhat differently, Bishop et al. [36] has theorized that mindfulness encompasses both attention to and 
acceptance of internal and external experiences, and that both psychological processes are beneficial to mental health. That is, regulating one's attention is believed to cultivate a non-elaborative awareness of thoughts and feelings as they emerge, rather than being caught up in ruminative thought processes about the origin or implications of the thoughts. Concurrently, embracing an attitude of acceptance towards unpleasant and painful thoughts and feelings is believed to alter the psychological context in which the events are experienced, thus, potentially reducing the perceived threat and unpleasantness of symptoms, and in turn, possibly leading to better affect tolerance and less reliance on avoidance strategies. However, our results and the results of Coffey et al. [37] suggest that it is ultimately the acceptance of one's current situation that is required to prevent the development of psychological distress in NHL patients and survivors and university students, respectively.

Nonetheless, attention to these thoughts and feelings will naturally precede the person's ability to accept the potentially stressful experiences. In this study, mindful-attention and mindful-acceptance were both associated with better QOL, suggesting that mindfully attending to one's thoughts and feelings may be sufficient to bolster one's sense of quality-of-life. However, it may be insufficient to buffer against the development of affective symptoms, in which case, mindful-acceptance of one's feelings, thoughts and events may be required.

The study results also generally accorded with those of experimental studies showing that acceptance-based treatments are effective in reducing psychological distress in end-stage cancer patients [50]. In addition, mindfulness-based stress reduction treatments have been shown to reduce depression, anxiety, distress [44] [46] [47], and high stress levels in cancer patients [48], as well as improve QOL [49] [51], sleep quality, energy levels, pain levels, and wellbeing [52]. However, in a recent randomized controlled trial of Tibetan yoga in patients with lymphoma that incorporated mindfulness techniques, depression and anxiety outcomes were not shown to improve, only some sleep parameters [53].

Finally, with regard to clinical relevance, the results of this study suggest that people with NHL may profit from the provision of psychological assistance to mindfully-accept their difficult situation, which may improve their ability to manage their feelings of distress. However, mindfully attending to one's thoughts and feelings may be sufficient to maintain QOL during times of high stress, although acceptance may be required, to buffer against the potential for distress. The study results also suggest that acceptance-based therapies may be most suitable for people with NHL, rather than other forms of mindfulness therapy (e.g., mindfulness-meditation, mindfulness-based stress reduction).

\subsection{Study Limitations and Future Directions}

The study results should be interpreted in light of several study limitations. First, the cross-sectional study design did not permit the analysis of causal relationships between the mindfulness constructs and other study variables. Thus, it is equally likely that depression, anxiety, high stress, and low QOL contributed to the experience of lower mindfulness levels, as it is that mindfulness levels impacted on the above states. Second, it is likely that variables such as emotion-regulation may have mediated the relationship between mindfulness and mental health, and may therefore have captured some of the variance in these psychological states, although such an enquiry was beyond the scope of this study. Third, most of the study participants were diagnosed with WM, a rare, indolent and mostly incurable form of NHL. Thus, the results may not be generalizable to patients with other forms of NHL.

Nonetheless, the sample size was adequate, the study employed psychometrically valid scales, and the mean age and medical characteristics of the participants were similar to prior published values. In terms of future indicated research, the relationship between mindfulness and mental health outcomes needs to be examined in a prospective longitudinal study or a randomized controlled trial of acceptance-based therapies, differing in terms of their clinical focus (e.g., mindfulness-based stress reduction vs. acceptance-based therapies). Second, to address other possible mechanisms, emotion regulation might be evaluated as a potential mediator or moderator of mindfulness to mental health outcome relationships. Third, future studies might also address experiences of trauma related psychological symptoms to determine if they co-vary with mindfulness levels, and examine whether mindfulness training may ameliorate symptoms of post-traumatic stress disorder.

\subsection{Conclusions}

Non-Hodgkin’s lymphoma (NHL) patients and survivors reported relatively low mean levels of depression, anxiety and stress, and high levels of trait mindfulness and quality of life. However, some participants reported 
ongoing anxiety and depression and impaired quality-of-life as a result of the illness, its treatment, or its implications. After controlling for potential third variables (i.e., marital and remission status), high trait mindfulness, and especially high mindful-acceptance were shown to be related to lower stress, anxiety, and depression levels. In contrast, both mindful-attention and mindful-acceptance were related to better QOL.

The results suggest that attending to one's thoughts and feelings may be sufficient to experience good quality of life, but it may be insufficient to buffer against the experience of psychological distress. Thus, the mindfulacceptance of unpleasant, threatening or painful thoughts and feelings may be necessary to buffer against the potential for depression, anxiety, and high perceived stress symptoms to be experienced. The results also suggest that acceptance-based treatments such as Acceptance and Commitment Therapy may assist distressed people with NHL.

\section{References}

[1] Australian Institute of Health and Welfare (2010) Cancer in Australia in 2010: An Overview.

[2] World Health Organisation (2005) Global Action against Cancer. http://www.who.int/cancer/media/en/792.pdf.

[3] National Cancer Institute (2008) SEER: Cancer Statistics Review, 1975-2008.http://seer.cancer.gov/csr/1975_2008/.

[4] American Cancer Society (2010) Cancer Facts and Figures 2010.

[5] Dimopoulos, M.A. and Alexanian, R. (1994) Waldenstrom’s Macroglobulinemia. Blood. http://bloodjournal.hematologylibrary.org/content/83/6/1452.full.pdf.

[6] Kaiser, N.C., Hartoonian, N. and Owen, J.E. (2010) Toward a Cancer-Specific Model of Psychological Distress: Population Data from the 2003-2005 National Health Interview Surveys. Journal of Cancer Survivorship, 4, 291-302. http://dx.doi.org/10.1007/s11764-010-0120-3

[7] Salander, P. (2010) Motives That Cancer Patients in Oncological Care Have for Consulting a Psychologist: An Empirical Study. Psycho-Oncology, 19, 248-254. http://dx.doi.org/10.1002/pon.1569

[8] Speca, M., Carlson, L.E., Mackenzie, M.J. and Angen, M. (2004) Mindfulness-Based Stress Reduction (MBSR) as an Intervention for Cancer Patients, in Mindfulness-Based Treatment Approaches: Clinician’s Guide to Evidence Base and Applications R Baer, Editor. Academic Press, Boston, 239-261.

[9] Cassileth, B.R., Lusk, E.J., Brown, L.L., Cross, P.A., Walsh, W.P. and Hurwitz, S. (1986) Factors Associated with the Psychological Distress in Cancer Patients. Medical Oncology, 14, 251-254. http://dx.doi.org/10.1002/mpo.2950140503

[10] Deimling, G.T., Kahana, B., Bowman, K.F. and Schaefer, M.L. (2002) Cancer Survivorship and Psychological Distress in Later Life. Psycho-Oncology, 11, 479-494. http://dx.doi.org/10.1002/pon.614

[11] Grassi, L. and Rosti, G. (1996) Psychosocial Morbidity and Adjustment to Illness among Long-Term Cancer Survivors. Psychosomatics, 37, 523-532. http://dx.doi.org/10.1016/S0033-3182(96)71516-5

[12] Jacobsen, P.B., Donovan, K.A., Trask, P.C., Fleishman, S.B., Zabora, J., Baker, F. and Holland, J.C. (2005) Screening for Psychological Distress in Ambulatory Cancer Patients. Cancer, 103, 1494-1502. http://dx.doi.org/10.1002/cncr.20940

[13] Linden, W., Vodermaier, A., Mackenzie, R. and Greig, D. (2012) Anxiety and Depression after Cancer Diagnosis: Prevalence Rates by Cancer Type, Gender, and Age. Journal of Affective Disorders, 141, 343-351. http://dx.doi.org/10.1016/j.jad.2012.03.025

[14] National Comprehensive Cancer Network (2006) NCCN Clinical Practice Guidelines in Oncology: Distress Management (Vol. 1). http://www.spitalmures.ro/_files/protocoale_terapeutice/oncologie/distress.pdf

[15] National Cancer Institute (2012) Post-Traumatic Stress Disorder. http://www.cancer.gov/cancertopics/pdq/supportivecare/post-traumatic-stress/Patient/page4

[16] Zabora, J., Brintzenhofeszoc, K., Curbow, B., Hooker, C. and Piantadosi, S. (2001) The Prevalence of Psychological Distress by Cancer Site. Psycho-Oncology, 10, 19-28. http://www.ncbi.nlm.nih.gov/pubmed/11180574 http://dx.doi.org/10.1002/1099-1611(200101/02)10:1<19::AID-PON501>3.0.CO;2-6

[17] Loge, J.H., Abrahamsen, A.F., Ekeberg, O., Hannisdal, E. and Kaasa, S. (1997) Psychological Distress after Cancer Cure: A Survey of 459 Hodgkin’s Disease Survivors. British Journal of Cancer, 76, 791-796. http://www.ncbi.nlm.nih.gov/pmc/articles/PMC2228046/pdf/brjcancer00170-0107.pdf http://dx.doi.org/10.1038/bjc.1997.464

[18] Fobair, P., Hoppe, R.T., Bloom, J., Cox, R., Varghese, A. and Spiegel, D. (1986) Psychosocial Problems among Survivors of Hodgkin's Disease. Journal of Clinical Oncology, 4, 805-814.

[19] Di Matteo, M.R., Lepper, H.S. and Crogan, T.W. (2000) Depression Is a Risk Factor for Noncompliance with Medical 
Treatment: Meta Analysis of the Effects of Anxiety and Depression on Patient Adherence. Archives of Internal Medicine, 160, 2101-2107.

[20] Walker, L.G., Heys, S.D., Walker, M.B., Ogston, K., Miller, I.D., Hutcheon, A.W., et al. (1999) Psychological Factors Can Predict the Response to Primary Chemotherapy in Patients with Locally Advanced Breast Cancer. European Journal of Cancer, 35, 1783-1788. http://dx.doi.org/10.1016/S0959-8049(99)00169-0

[21] Cheung, W.Y., Le, L.W., Gagliese, L. and Zimmermann, C. (2011) Age and Gender Differences in Symptom Intensity and Symptom Clusters among Patients with Metastatic Cancer. Supportive Care in Cancer, 19, 417-423. http://dx.doi.org/10.1007/s00520-010-0865-2

[22] Thomas, B.C., NandaMohan, V., Nair, M.K. and Pandey, M. (2010) Gender, Age and Surgery as a Treatment Modality Leads to Higher Distress in Patients with Cancer. Supportive Care in Cancer, 19, 239-250. http://dx.doi.org/10.1007/s00520-009-0810-4

[23] Brown, K.W., Levy, A., Rosberger, Z. and Edgar, L. (2003) Psychological Distress and Cancer Survival: A Follow-Up Ten Years after Diagnosis. Psychosomatic Medicine, 65, 636-643. http://dx.doi.org/10.1097/01.PSY.0000077503.96903.A6

[24] Faul, L.A., Jim, H.S., Williams, C., Loftus, L. and Jacobsen, P.B. (2010) Relationship of Stress Management Skill to Psychological Distress and Quality of Life in Adults with Cancer. Psycho-Oncology, 19, 102-109. http://dx.doi.org/10.1002/pon.1547

[25] Skarstein, J., Aass, N., Fossa, S., Skovlund, E. and Dahl, A. (2000) Anxiety and Depression in Cancer Patients: Relation between the Hospital Anxiety and Depression Scale and the European Organization for Research and Treatment of Cancer Core Quality of Life Questionnaire. Journal of Psychosomatic Research, 49, 27-34. http://dx.doi.org/10.1016/S0022-3999(00)00080-5

[26] Burgess, C., Cornelius, V., Love, S., Graham, J., Richards, M. and Ramirez, A. (2005) Depression and Anxiety in Women with Early Breast Cancer: Five Year Observational Cohort Study. British Medical Journal, 330, 702-705. http://dx.doi.org/10.1136/bmj.38343.670868.D3

[27] Merckaert, I., Libert, Y., Messin, S., Milani, M., Slachmuylder, J.L. and Razavi, D. (2010) Cancer Patients’ Desire for Psychological Support: Prevalence and Implications for Screening Patients' Psychological Needs. Psycho-Oncology, 19, 141-149. http://dx.doi.org/10.1002/pon.1568

[28] Bellizzi, K.M., Miller, M.F., Arora, N.K. and Rowland, J.H. (2007) Positive and Negative Life Changes Experienced by Survivors of Non-Hodgkin's Lymphoma. Annals of Behavioral Medicine, 34, 188-199. http://dx.doi.org/10.1007/BF02872673

[29] Deshields, T., Tibbs, T., Fan, M.Y. and Taylor, M. (2006) Differences on Patterns of Depression after Treatment for Breast Cancer. Psycho-Oncology, 15, 398-406. http://dx.doi.org/10.1002/pon.962

[30] Floortje, M., Aaronson, N.K., Vingerhoets, A.J.J.M., Coebergh, J.W.W., Vreugdenhil, G., Lybeert, M.L.M. and van de Poll-Franse, L.V. (2007) Quality of Life among Long-Term Non-Hodgkin's Lymphoma Survivors: A PopulationBased Study. Cancer, 109, 1659-1667. http://dx.doi.org/10.1002/cncr.22581

[31] Grossman, P., Niemann, L., Schmidt, S. and Walach, H. (2004) Mindfulness-Based Stress Reduction and Health Benefits: A Meta-Analysis. Journal of Psychosomatic Research, 57, 35-43. http://dx.doi.org/10.1016/S0022-3999(03)00573-7

[32] Thera, N. (1962) The Heart of Buddhist Meditation. Weiser, New York.

[33] Kabat-Zinn, J. (1994) Wherever You Go, There You Are: Mindfulness Meditation in Everyday Life. Delacorte, New York.

[34] Brown, K.W. and Ryan, R.M. (2003) The Benefits of Being Present: Mindfulness and Its Role in Psychological Well-Being. Journal of Personality and Social Psychology, 84, 822-848. http://dx.doi.org/10.1037/0022-3514.84.4.822

[35] Baer, R.A., Smith, G.T., Hopkins, J., Krietemeyer, J. and Toney, L. (2006) Using Self-Report Assessment Methods to Explore Facets of Mindfulness. Assesssment, 13, 27-45. http://dx.doi.org/10.1177/1073191105283504

[36] Bishop, S.R., Lau, M., Shapiro, S., Carlson, L., Anderson, N.D., Carmody, J., et al. (2004) Mindfulness: A Proposed Operational Definition. Clinical Psychology: Science and Practice, 11, 230-241. http://dx.doi.org/10.1093/clipsy.bph077

[37] Coffey, K.A., Hartman, M. and Fredrickson, B.L. (2010) Deconstructing Mindfulness and Constructing Mental Health: Understanding Mindfulness and Its Mechanisms of Action. Mindfulness, 1, 235-253. http://dx.doi.org/10.1007/s12671-010-0033-2

[38] Carlson, L.E. and Brown, K.W. (2005) Validation of the Mindful Attention Awareness Scale in a Cancer Population. Journal of Psychosomatic Research, 58, 29-33. http://dx.doi.org/10.1016/j.jpsychores.2004.04.366

[39] Faul, F., Erdfelder, E., Buchner, A. and Lang, A.G. (2009) Statistical Power Analyses Using G*Power 3.1: Tests for 
Correlation and Regression Analyses. Behavior Research Methods, 41, 1149-1160. http://dx.doi.org/10.3758/BRM.41.4.1149

[40] Cohen, J., Cohen, P., West, S. and Aiken, L. (2003) Applied Multiple Regression/Correlation Analysis for the Behavioral Sciences. 3rd Edition, Lawrence Erlbaum Associates, Mahwah.

[41] Lovibond, P.F. and Lovibond, S.H. (1995) The Structure of Negative Emotional States: Comparison of the Depression Anxiety Stress Scales (DASS) with the Beck Depression and Anxiety Inventories. Behaviour Research and Therapy, 33, 335-343. http://dx.doi.org/10.1016/0005-7967(94)00075-U

[42] Antony, M.M., Beiling, P.J., Cox, B.J., Enns, M.W. and Swinson, R.P. (1998) Psychometric Properties of the 42-Item and 21-Item Versions of the Depression, Anxiety, Stress Scales in Clinical Groups and a Community Sample. Psychological Assessment, 10, 176-181. http://dx.doi.org/10.1037/1040-3590.10.2.176

[43] Cella, D.F., Tulsky, D.S., Gray, G., Sarafian, B., Linn, E., Bonomi, A., et al. (1993) The Functional Assessment of Cancer Therapy Scale: Development and Validation of the General Measure. Journal of Clinical Oncology, 11, 570579.

[44] Foley, E., Baillie, A., Huxter, M., Price, M. and Sinclair, E. (2010) Mindfulness-Based Cognitive Therapy for Individuals Whose Lives Have Been Affected by Cancer: A Randomized Controlled Trial. Journal of Consulting and Clinical Psychology, 78, 72-79. http://dx.doi.org/10.1037/a0017566

[45] Field, A.P. (2009) Discovering Statistics Using SPSS. 2nd Edition, Sage, London.

[46] Speca, M., Carlson, L., Goodey, E. and Angen, M. (2000) A Randomized Wait-List Controlled Trial: The Effect of a Mindfulness Meditation-Based Stress Reduction Program on Mood and Symptoms of Stress in Cancer Outpatients. Psychosomatic Medicine, 62, 613-622. http://dx.doi.org/10.1097/00006842-200009000-00004

[47] Lengacher, C.A., Johnson-Mallard, V., Post-White, J., Moscoso, M.S., Jacobsen, P.B., Klein, T.W., et al. (2009) Randomized Controlled Trial of Mindfulness-Based Stress Reduction (MBSR) for Survivors of Breast Cancer. PsychoOncology, 18, 1261-1272. http://dx.doi.org/10.1002/pon.1529

[48] Branstrom, R., Brandberg, Y. and Moskowitz, J.T. (2010) Self-Report Mindfulness as a Mediator of Psychological Well-Being in a Stress Reduction Intervention for Cancer Patients: A Randomized Study. Annals of Behavioral Medicine, 39, 151-161. http://dx.doi.org/10.1007/s12160-010-9168-6

[49] Ramachandra, P., Booth, S., Pieters, T., Vrotsou, K. and Huppert, F.A. (2009) A Brief Self-Administered Psychological Intervention to Improve Well-Being in Patients with Cancer: Results from a Feasibility Study. Psycho-Oncology, 18, 1323-1326. http://dx.doi.org/10.1002/pon.1516

[50] Branstetter, A.D., Wilson, K.G., Hildebrandt, M. and Mutch, D. (2004) Improving Psychological Adjustment among Cancer Patients: ACT and CBT. The Meeting of the Association for Advancement of Behavior Therapy, New Orleans.

[51] Carlson, L.E., Speca, M., Patel, K.D. and Goodey, E. (2003) Mindfulness-Based Stress Reduction in Relation to Quality of Life, Mood, Symptoms of Stress, and Immune Parameters in Breast and Prostate Cancer Outpatients. Psychosomatic Medicine, 65, 571-581. http://dx.doi.org/10.1097/01.PSY.0000074003.35911.41

[52] Kvillemo, P. and Bränström, R. (2011) Experiences of a Mindfulness-Based Stress-Reduction Intervention among Patients with Cancer. Cancer Nursing, 34, 24-31. http://dx.doi.org/10.1097/NCC.0b013e3181e2d0df

[53] Cohen, L., Warneke, C., Fouladi, R.T., Rodriguez, M.A. and Chaoul-Reich, A. (2004) Psychological Adjustment and Sleep Quality in a Randomized Trial of the Effects of a Tibetan Yoga Intervention in Patients with Lymphoma. Cancer, 100, 2253-2260. http://dx.doi.org/10.1002/cncr.20236 
Scientific Research Publishing (SCIRP) is one of the largest Open Access journal publishers. It is currently publishing more than 200 open access, online, peer-reviewed journals covering a wide range of academic disciplines. SCIRP serves the worldwide academic communities and contributes to the progress and application of science with its publication.

Other selected journals from SCIRP are listed as below. Submit your manuscript to us via either submit@scirp.org or Online Submission Portal.
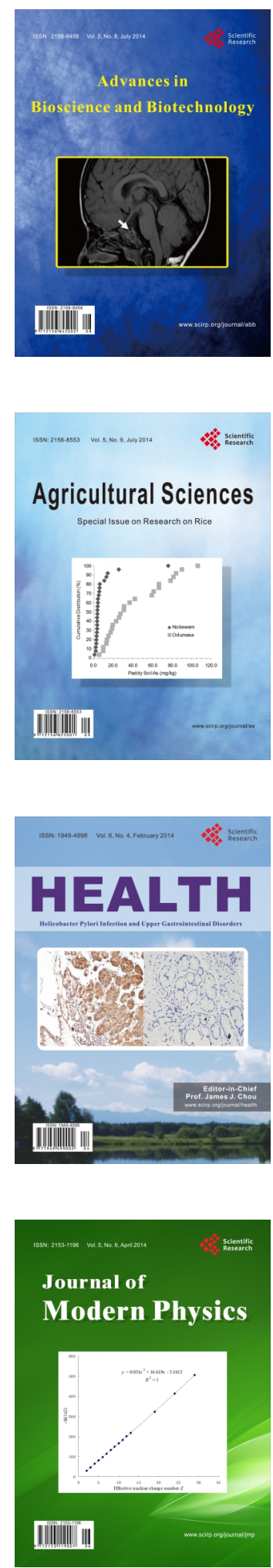
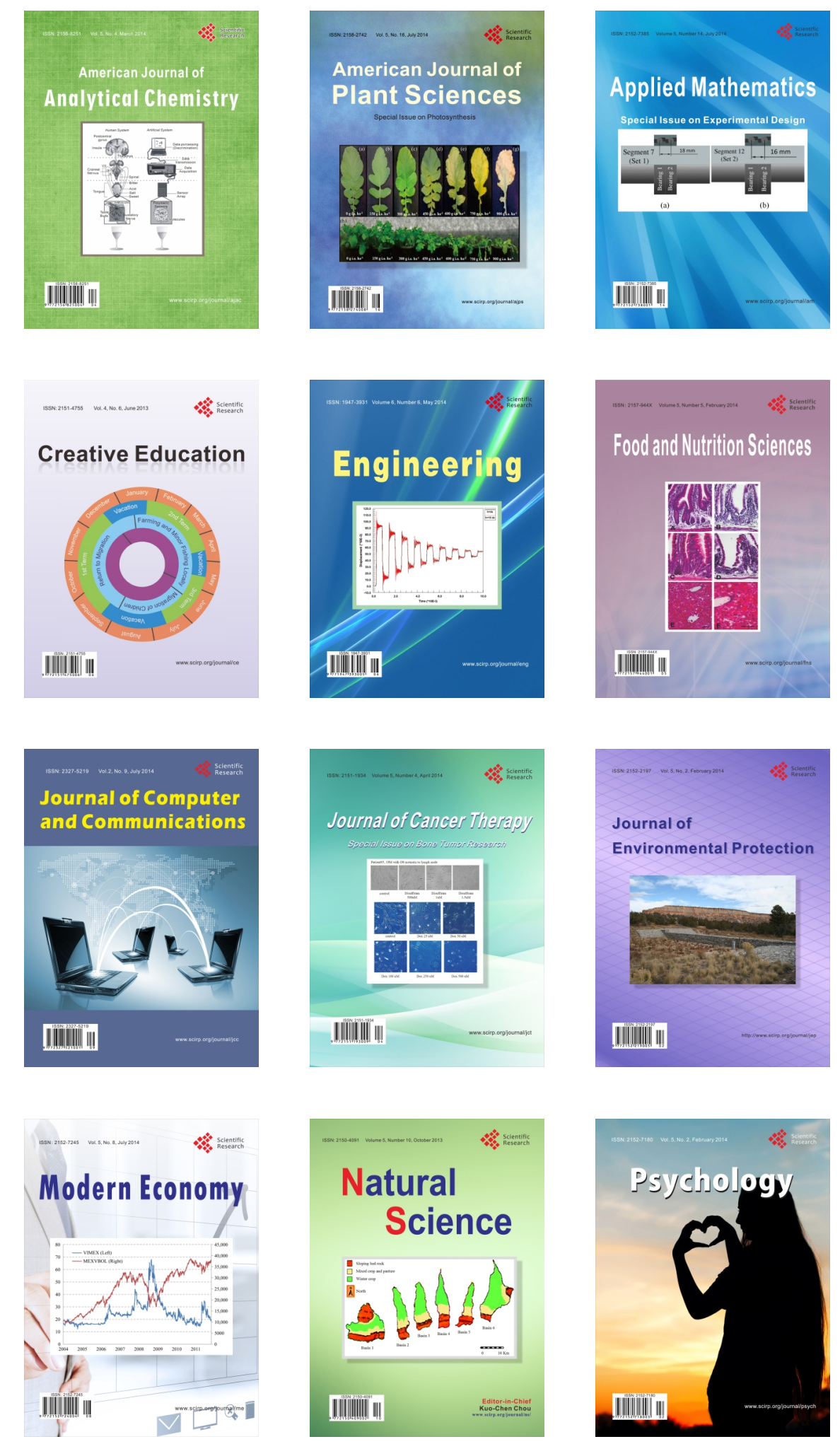